\title{
Fibroblast growth factor 21 (FGF21) is a sensitive marker of osteoporosis in haemodialysis patients: a cross-sectional observational study
}

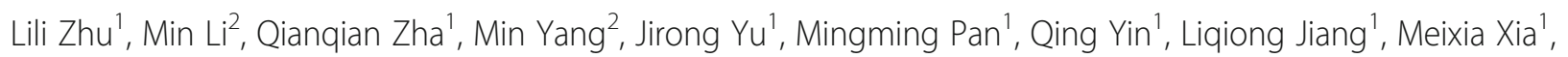
Bi-Cheng Liu ${ }^{1 *}$ and Bin Wang ${ }^{1 *}$

\begin{abstract}
Introduction: Osteoporosis is one of the important bone abnormalities in chronic kidney disease-mineral and bone disorder (CKD-MBD) and still lacks a sensitive biomarker to diagnose. Fibroblast growth factor 21 (FGF21) can stimulate bone loss in patients with diabetes and increase in CKD patients. In this study, we investigated whether FGF21 could serve as a biomarker to predict osteoporosis in a haemodialysis cohort.

Methods: We recorded demographic information, biochemical data, and serum FGF21 and FGF23 levels and measured the $C T$ attenuation values of 339 haemodialysis patients from two large medical centres. We assessed the correlation of CT attenuation values with serum FGF21 and FGF23 levels and tested whether they were independent factors for osteoporosis. ROC curves were constructed to compare the prognostic value of FGF21 and FGF23 for osteoporosis.

Results: Based on the CT attenuation value, serum FGF21 levels were higher in our osteoporosis group (median $640.86 \mathrm{pg} / \mathrm{ml}$ vs. $245.46 \mathrm{pg} / \mathrm{ml}, P<0.01)$. Meanwhile, FGF21 $(r=-0.136, P<0.05)$ and FGF23 $(r=-0.151, P<0.05)$ were both negatively associated with osteoporosis. Moreover, FGF21 ( $\beta=-0.067, P<0.05)$ was an independent factor for osteoporosis. Furthermore, FGF21 combined with age yielded a marked specificity ( $90.5 \%)$ and sensitivity $(61.8 \%)$ in predicting osteoporosis of haemodialysis patients with less residual renal function.

Conclusions: FGF21 has a positive relationship with the incidence of osteoporosis in patients on haemodialysis. FGF21 combined with age is a good predictive biomarker for osteoporosis in patients on haemodialysis, especially those with less residual renal function.
\end{abstract}

Keywords: Osteoporosis, Fibroblast growth factor 21, CT attenuation values, Haemodialysis, CKD-MBD

\footnotetext{
*Correspondence: liubc64@163.com; wangbinhewei@126.com

${ }^{1}$ Institute of Nephrology, Zhong Da Hospital, Southeast University School of Medicine, Nanjing, Jiangsu, China

Full list of author information is available at the end of the article
}

C C The Author(s). 2021 Open Access This article is licensed under a Creative Commons Attribution 4.0 International License, which permits use, sharing, adaptation, distribution and reproduction in any medium or format, as long as you give appropriate credit to the original author(s) and the source, provide a link to the Creative Commons licence, and indicate if changes were made. The images or other third party material in this article are included in the article's Creative Commons licence, unless indicated otherwise in a credit line to the material. If material is not included in the article's Creative Commons licence and your intended use is not permitted by statutory regulation or exceeds the permitted use, you will need to obtain permission directly from the copyright holder. To view a copy of this licence, visit http://creativecommons.org/licenses/by/4.0/ The Creative Commons Public Domain Dedication waiver (http://creativecommons.org/publicdomain/zero/1.0/) applies to the data made available in this article, unless otherwise stated in a credit line to the data. 


\section{Introduction}

Chronic kidney disease-mineral and bone disorder (CKDMBD), a systemic disorder of mineral and bone metabolism [1], has a high prevalence and morbidity in patients with CKD [2], especially in patients with end-stage renal disease (ESRD) [3]. CKD-MBD is composed of three main aspects: renal bone disease, vascular or other soft-tissue calcification, and biochemical abnormalities such as calcium, phosphate, parathyroid hormone (PTH), and fibroblast growth factor 23 (FGF23) [4]. Osteoporosis characterized by low bone mineral density and reduced mechanical strength [5] is the most clinically relevant feature of renal bone disease. As reported, individuals with early stages of CKD may have a higher prevalence of osteoporosis and fracture risk compared to non-CKD and $20 \%$ mortality from hip fractures within the first year [6-8]. Many factors, such as secondary hyperparathyroidism, vitamin D deficiency, increased FGF23, and metabolic acidosis, are involved in the pathophysiology of subsequent osteoporosis in patients with CKD [9].

The FGF19 subfamily, composed of FGF19, FGF21, and FGF23, is involved in diverse metabolic regulation of interorgan endocrine signalling axes [10]. FGF23 is a $32-\mathrm{kDa}$ glycoprotein secreted by osteocytes and functions in calcium and phosphorus metabolism disorders [11], bone loss [12], vascular calcification [13] and other CKD-MBD events in patients with ESRD. In previous studies, some scholars proposed that FGF23 could predict bone loss in patients with ESRD through its strong correlation with bone mineral density (BMD) in lumbar spine sites and femoral neck sites [14, 15]. However, Wohlfahrt $\mathrm{P}$ and Isakova $\mathrm{T}$ et al. drew contradictory conclusions that FGF23 had no correlations with BMD and bone mass corrected for other factors such as height, eGFR and PTH levels [16, 17]. Therefore, the role of FGF23 in the changes in BMD in patients with CKD is still controversial. FGF21, another member of the FGF19 subfamily, is a powerful regulator of glucose and lipid metabolism and is mainly expressed in the liver $[18,19]$. FGF21 is excreted primarily by the kidney, and its level increases markedly in patients with impaired renal function [20]. In animal models, genetic FGF21 overexpression decreases bone mass, and systemic FGF21 treatment leads to severe bone loss [21]. Meanwhile, FGF21 can accelerate bone loss by potentiating the effects of peroxisome proliferator-activated receptor $\gamma$ [21]. Moreover, higher FGF21 levels synthesized in the liver can induce insulin-like growth factor binding protein 1 (IGFBP1) to stimulate osteoclast differentiation and bone resorption [18]. However, the association of FGF21 with bone loss in CKD has rarely been explored in previous studies.

In the present study, we evaluated the relationship between FGF21 and FGF23 and osteoporosis in a population-based retrospective HD cohort. First, we compared the serum FGF21 and FGF23 levels in patients on HD with or without osteoporosis on the basis of CT attenuation values. Second, we clarified whether FGF21 and FGF23 were independently associated with CT attenuation values. Ultimately, we explored the predictive values of serum FGF21 and FGF23 on osteoporosis in our HD cohort.

\section{Materials and methods}

\section{Study design and subjects}

This was a cross-sectional observational study composed of 339 patients on HD from two large haemodialysis centres, Nanjing Zhongda Hospital and the First People's Hospital of Changzhou, from January 2018 to December 2019 (Fig. 1). The exclusion criteria were as follows: (1) age not within 18 to 90 years old, (2) acute phase of infections, (3) malignancy, (4) parathyroidectomy history, (5) hepatobiliary disease history, (6) other acute illnesses, and (7) decline to participate in this study. All enrolled patients had received regular dialysis $(3 \sim 4$ times per week) for at least one month. The study protocol was approved by the Ethics Committee of Zhongda Hospital affiliated with Southeast University, and the study was conducted in accordance with the Helsinki Declaration and Chinese law. The details of the study were explained to every patient; a signed informed consent was obtained from all subjects. We confirmed that all methods were carried out in accordance with relevant guidelines and regulations.

\section{Clinical and biochemical data}

Blood samples containing haemoglobin $(\mathrm{Hb})$, serum albumin (Alb), uric acid, calcium $(\mathrm{Ca})$, phosphate (Pi), total cholesterol (TC), triglyceride (TG), dicarbonate and intact parathyroid hormone (iPTH) were collected before dialysis and measured via routine laboratory methods. Serum iPTH was measured by Electrochemiluminescence Technology (Cobase411 analyser, Germany, Roche Diagnostics ${ }^{\circ}$ ). This method is an immunological test for the quantitative determination of iPTH. The interassay coefficient of variation for $\mathrm{iPTH}$ was lower than $4 \%$. We also recorded the comorbidities (hypertension, diabetes mellitus and cardiocerebrovascular disease [CVD]) and medical usages (calcium supplements, vitamin D, $\mathrm{ACEI} / \mathrm{ARB}$ and cinacalcet) for every individual by checking their medical records.

\section{Measurement of serum FGF21 and FGF23 in patients on HD}

Blood samples were collected under the fasting overnight and before dialysis. They were withdrawn in 


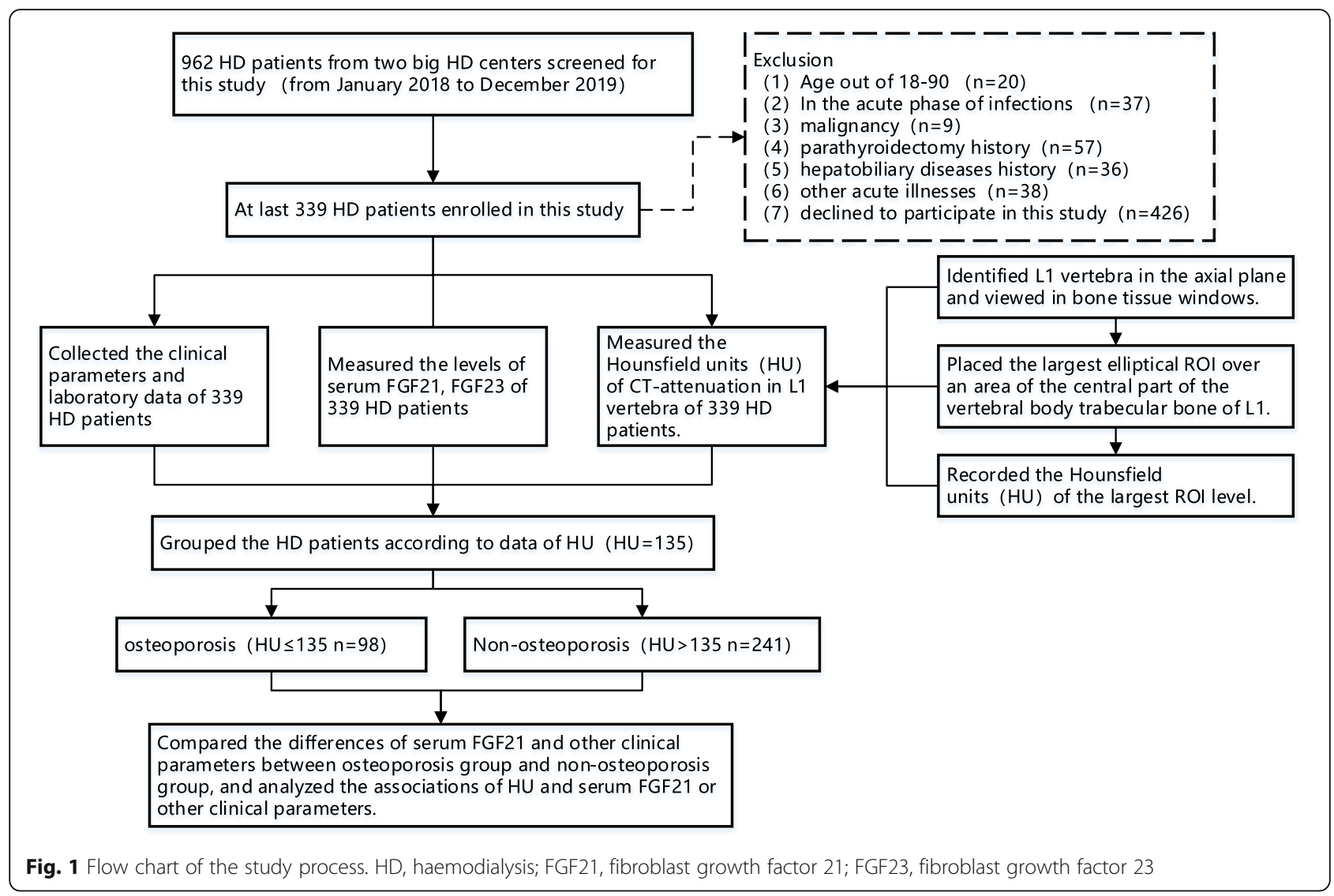

vacuum tubes and then centrifuged at $3000 \mathrm{rpm}$ for $10 \mathrm{~min}$. The upper serum was collected and stored at $-80{ }^{\circ} \mathrm{C}$ immediately for future analyses. Serum FGF21 and FGF23 levels were assessed by enzyme-linked immunosorbent assay (ELISA) kits for human FGF21 (Neobioscience, China) and for human FGF23 (Joyee biotechnics, China), respectively. The interassay and intraassay coefficients of variation were both less than $10 \%$ for FGF21 and FGF23.

\section{Attenuation assessment on CT scans}

Discovery HD 750 64-slice CT (GE Health care, USA) was used to measure osteoporosis. We identified the L1 vertebra in the axial plane and viewed it in bone tissue

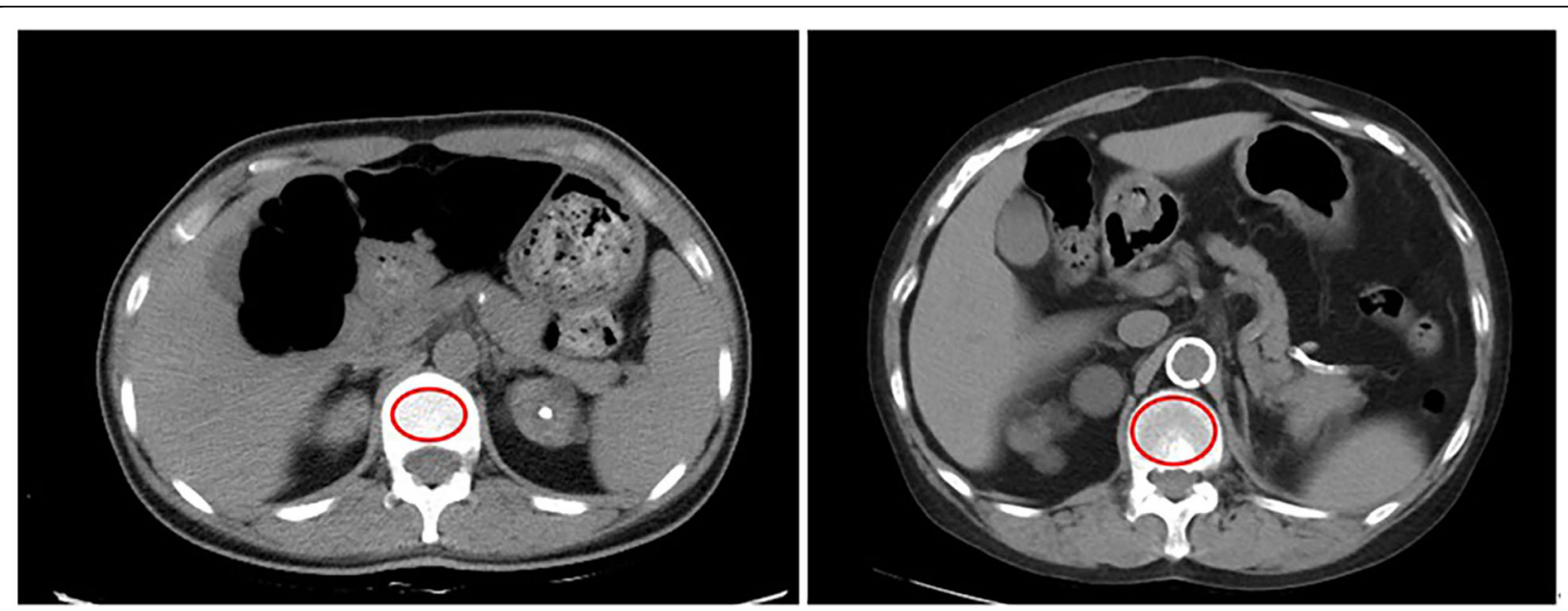

Fig. 2 Axial image through the vertebral body of $L 1$ on a thoracoabdominal-pelvic CT scan. Placement of the region of interest within the trabecular bone and assessment of the CT attenuation value in Hounsfield units (182.3 HU left and $96.5 \mathrm{HU}$ right in this example) 
windows. Then, we placed the largest elliptical ROI on an area of the central part of the vertebral body trabecular bone of L1 to measure the vertebral BMD. In this process, the cortical margins should be excluded to prevent volume averaging, as shown in Fig. 2 . All CT scans were performed by a single observer and the same CT machine to ensure consistency of regions. The mean CT attenuation values for each patient were measured in HU. We defined CT attenuation values less than 135 HU as osteoporosis [22].

\section{Statistical analyses}

Statistical analyses were performed using SPSS 18.0 software. The data are given as the mean \pm SD for normally distributed variables and as the median and interquartile range for non-normally distributed variables. Univariate analyses were performed to compare the differences between two groups. Meanwhile, we used bivariate correlation analyses to assess the correlation of $\mathrm{CT}$ attenuation with serum FGF21 and other clinical parameters. We employed stepwise multivariate linear regression analyses to evaluate the independent association of variables with L1 attenuation. ROC curves were constructed to calculate the AUC and compared the prognostic value of every independently associated factor or group of factors to osteoporosis. All analyses were two-tailed, and a $P$ value $<0.05$ was considered to be statistically significant.

\section{Results}

\section{General characteristics of subjects}

In this cross-sectional study, of the 962 patients on HD screened, a total of 339 patients were eligible (193 men, $56.5 \%$ ) with a mean (SD) age of 56.79 (15.60) years (Table 1). In the process of data collection, 89 patients lack blood data and 124 patients lack CT scans, we excluded 213 patients for the accuracy of our study. The dialysis duration was $4.33 \pm 4.91$ years, and the body mass index was $22.99 \pm$ $4.01 \mathrm{~kg} / \mathrm{m}^{2}$. According to the threshold of osteoporosis (CT attenuation values $\leq 135 \mathrm{HU}$ ) proposed by Pickhardt et al. [22], $98(28.9 \%)$ patients were enrolled in the osteoporosis group, and 241 (71.1\%) were enrolled in the nonosteoporosis group. The basic characteristics of all patients divided into these two groups are presented in Table 1. In the osteoporosis group, patients on HD had a mean age of $66.45 \pm 13.28$ years and a median serum FGF21 level of $640.86 \mathrm{pg} / \mathrm{ml}$ (interquartile range 1.72, 3176.14). In the nonosteoporosis group, patients had a mean age of $52.86 \pm$ 14.77 years and a median serum FGF21 level of $245.46 \mathrm{pg} /$ $\mathrm{ml}$ (interquartile range 0.95, 1764.29). As shown in Table 1, there were significant differences in age, diastolic blood pressure (DBP), and vitamin $\mathrm{D}$ usage rate between these two groups (all $P<0.05$ ). Serum FGF21 levels were significantly higher in the osteoporosis group $(P<0.001)$, while serum
FGF23 levels were not significantly different between these two groups. Additionally, the percentage of patients who suffered diabetes and cardiocerebrovascular disease (CVD) in the osteoporosis group was higher than that in the nonosteoporosis group $(P<0.001)$. The baseline characteristics based on the FGF21 median were shown in Table 2. Compared to low serum FGF21group, hemoglobin, albumin and dicarbonate levels were all significantly lower in high serum FGF21 level group $(P<0.05)$. Meanwhile, the proportion of HD patients with hypertension in high serum FGF21 level group is less than that in low serum FGF21 group $(P<0.05)$. However, the CT attenuation had no statistical difference between the two groups.

\section{Correlations of CT attenuation values with FGF21 and FGF23 in HD patients}

In all patients on HD, serum FGF21 and FGF23 levels were both negatively related to CT attenuation values (FGF21: $r_{1}=-0.136, P_{1}=0.012 ;$ FGF23: $\left.r_{2}=-0.151, P_{2}=0.005\right)$. In our osteoporosis group, CT attenuation and Log (FGF21) were normally distributed data and CT attenuation values were also negatively associated with Log (FGF21) $(r=-0.238$, $P=0.019$ ) in pearson correlation analysis (Fig. 3). Univariate logistic regression analysis also showed that $\mathrm{CT}$ attenuation is negatively associated with above-tertile serum FGF21 levels (odds ration $[\mathrm{OR}]=0.420, P<0.001$ ) (Supplemental Table 1). In addition, $C T$ attenuation values were negatively correlated with age $(r=-0.440, P<0.001)$ and dialysis duration $(r=-0.120, P=0.028)$, while the CT attenuation values were positively correlated with DBP $(r=0.274, P<$ 0.001), as shown in Table 3.

\section{Multivariate linear regression analyses for independently associated factors of CT attenuation values and serum FGF21 levels}

Those parameters that were different between the osteoporosis and non-osteoporosis groups and well-known risk factors, such as dialysis duration, SBP, Hb, Alb, TG, $\mathrm{Ca}, \mathrm{Pi}, \mathrm{iPTH}$ and FGF23, were all included in multivariate linear regression analyses. As shown in Table 4, only FGF21 $(\beta=-0.067, P<0.05)$, age $(\beta=-1.362, P<0.05)$ and DM $(\beta=-27.013, P<0.05)$ were independently and negatively associated with $C T$ attenuation in patients on HD. Meanwhile, albumin $(\beta=-0.062, P<0.001)$, dicarbonate $(\beta=-0.079, P<0.001)$, calcium $(\beta=0.796, P<$ 0.05), CT attenuation $(\beta=-0.519, P<0.05)$ and comorbidity of hypertension $(\beta=-0.575, P<0.05)$ were independently associated with serum FGF21 levels in patients on HD, as shown in Table 5. In multivariate logistic regression analysis, $\mathrm{CT}$ attenuation is positively associated with age $(\mathrm{OR}=1.065, P<0.001)$ and FGF21 levels $(\mathrm{OR}=1.002, P<0.001)($ Supplemental Table 2). 
Table 1 Comparison of clinical characteristics and laboratory data between the osteoporosis and non-osteoporosis groups in patients on HD

\begin{tabular}{|c|c|c|c|c|}
\hline & $\begin{array}{l}\text { All HD } \\
\text { patients }\end{array}$ & osteoporosis & $\begin{array}{l}\text { non- } \\
\text { osteoporosis }\end{array}$ & $P$ value \\
\hline Number & 339 & 98 & 241 & \\
\hline \multicolumn{5}{|l|}{ General data } \\
\hline Age(years) & $56.79 \pm 15.60$ & $66.45 \pm 13.28$ & $52.86 \pm 14.77$ & $<0.001^{* *}$ \\
\hline Sex(male \%) & $193(56.93 \%)$ & $60(61.22 \%)$ & $133(55.19 \%)$ & 0.309 \\
\hline Dialysis vintage(years) & $4.33 \pm 4.91$ & $4.63 \pm 4.87$ & $4.21 \pm 4.94$ & 0.469 \\
\hline Body mass index(BMI) & $22.99 \pm 4.01$ & $22.93 \pm 4.03$ & $23.01 \pm 4.01$ & 0.868 \\
\hline Systolic BP(mmHg) & $145.78 \pm 24.40$ & $145.94 \pm 24.37$ & $145.72 \pm 24.46$ & 0.940 \\
\hline Diastolic BP(mmHg) & $82.32 \pm 14.60$ & $78.51 \pm 14.55$ & $83.87 \pm 14.36$ & $0.002^{* *}$ \\
\hline \multicolumn{5}{|l|}{ Blood data } \\
\hline Hemoglobin(g/L) & $97.57 \pm 20.14$ & $98.47 \pm 20.94$ & $97.20 \pm 19.84$ & 0.601 \\
\hline Albumin(g/L) & $35.89 \pm 6.13$ & $35.36 \pm 6.41$ & $36.11 \pm 6.02$ & 0.309 \\
\hline Uric acid(mmol/L) & $378.64 \pm 125.83$ & $\begin{array}{l}368.83 \pm \\
120.70\end{array}$ & $382.63 \pm 127.89$ & 0.361 \\
\hline Triglycerides(mmol/L) & $1.81 \pm 1.37$ & $1.75 \pm 1.45$ & $1.84 \pm 1.33$ & 0.438 \\
\hline Total cholesterol(mmol/L) & $4.13 \pm 1.12$ & $4.06 \pm 1.00$ & $4.16 \pm 1.17$ & 0.605 \\
\hline Dicarbonate(mmol/L) & $22.65 \pm 3.76$ & $22.63 \pm 3.87$ & $22.66 \pm 3.72$ & 0.943 \\
\hline Calcium(mmol/L) & $2.26 \pm 0.24$ & $2.28 \pm 0.25$ & $2.26 \pm 0.24$ & 0.548 \\
\hline Phosphate(mmol/L) & $1.70(0.19,4.16)$ & $1.69(0.28,4.16)$ & $1.76(0.19,3.35)$ & 0.305 \\
\hline Parathormon(pg/ml) & $374.07 \pm 418.87$ & $\begin{array}{l}347.02 \pm \\
385.80\end{array}$ & $385.07 \pm 431.87$ & 0.449 \\
\hline FGF21 quartiles (pg/ml) & 386.67 & 930.23 & 288.80 & $<0.001^{* *}$ \\
\hline $\begin{array}{l}\text { FGF23 quartiles }(\mathrm{pg} / \mathrm{ml}) 9309.83 \pm 10410.899529 .83 \pm 9485.399220 .37 \pm \\
10782.060 .804\end{array}$ & 13116.71 & 16210.65 & 13189.01 & 0.804 \\
\hline \multicolumn{5}{|l|}{ Comorbidity } \\
\hline Diabetes(\%) & $112(33.04 \%)$ & $45(45.92 \%)$ & $67(27.80 \%)$ & $0.001^{* *}$ \\
\hline Hypertension(\%) & 298(87.91\%) & $87(88.78 \%)$ & $211(87.55 \%)$ & 0.754 \\
\hline CVD(\%) & $94(27.73 \%)$ & $48(48.98 \%)$ & $46(19.09 \%)$ & $<0.001^{* *}$ \\
\hline \multicolumn{5}{|l|}{ Medicine usage } \\
\hline Vitamin D(\%) & $151(44.54 \%)$ & $31(31.63 \%)$ & $120(49.79 \%)$ & $0.002^{* *}$ \\
\hline Calciu supplements(\%) & $86(25.37 \%)$ & $22(22.45 \%)$ & $64(26.56 \%)$ & 0.431 \\
\hline Cinacalcet(\%) & $52(15.34 \%)$ & $11(11.22 \%)$ & $41(17.01 \%)$ & 0.180 \\
\hline ACEI/ARB(\%) & $94(27.73 \%)$ & $28(28.57 \%)$ & $66(27.39 \%)$ & 0.825 \\
\hline \multicolumn{5}{|l|}{$\operatorname{FRAX}(306)^{a}$} \\
\hline Major Osteoporosis & $3(0.9,14)$ & $4.0(1.0,13.0)$ & $2.55(0.9,14)$ & $<0.001^{* *}$ \\
\hline Hip fracture & $0.8(0.0,10.0)$ & $1.95(0,10)$ & $0.5(0,10)$ & $<0.001^{* *}$ \\
\hline
\end{tabular}

The values are shown as the mean $\pm \mathrm{SD}$, median (interquartile range) or numbers (\%), ${ }^{*} P<0.05$, ${ }^{* *} P<0.01$.

${ }^{a} 306$ of 339 patients agreed to complete the FRAX questionnaire.

HD haemodialysis; BP blood pressure; FGF21 fibroblast growth factor 21; FGF23 fibroblast growth factor 23; CVD cardiocerebrovascular disease; ACEI angiotensinconverting enzyme; $A R B$ angiotensin receptor II antagonist; FRAX fracture risk assessment tool

\section{Prediction by FGF21 and FGF23 of osteoporosis in patients on HD}

In this study, receiver operating characteristic (ROC) curves were constructed to assess distinguished values of independently associated factors in predicting osteoporosis (Table 6). The area under the curve (AUC) of FGF21 in predicting osteoporosis was 0.71 (95\% CI, 0.64 to $0.78, P<$ $0.001)$, with good sensitivity $(80.2 \%)$ but low specificity (41.1\%). Notably, the AUC of FGF21 combined with age in predicting osteoporosis increased significantly to 0.829 ( $95 \% C I, 0.78$ to $0.88, P<0.001$ ) with optimal sensitivity $(91.4 \%)$ and higher specificity $(47.9 \%)$. In the two 
Table 2 Comparison of clinical characteristics and laboratory data between the low serum FGF21 level group and high serum FGF21 level group in patients on HD

\begin{tabular}{|c|c|c|c|}
\hline & $\begin{array}{l}\text { Low FGF21 group } \\
\text { ( FGF21 } \leq 184.50 \mathrm{pg} / \mathrm{ml} \text { ) }\end{array}$ & $\begin{array}{l}\text { High FGF21 group } \\
\text { ( FGF21>184.50pg/ml ) }\end{array}$ & $P$ value \\
\hline Number & 170 & 169 & \\
\hline \multicolumn{4}{|l|}{ General data } \\
\hline Age(years) & $55.82 \pm 15.60$ & $57.76 \pm 15.59$ & 0.253 \\
\hline Sex(male \%) & $100(58.82 \%)$ & $93(55.03 \%)$ & 0.481 \\
\hline Dialysis vintage(years) & $4.17 \pm 4.45$ & $4.49 \pm 5.35$ & 0.540 \\
\hline Body mass index(BMI) & $22.93 \pm 3.93$ & $23.05 \pm 4.09$ & 0.794 \\
\hline Systolic BP(mmHg) & $145.75 \pm 24.91$ & $145.82 \pm 23.95$ & 0.979 \\
\hline Diastolic BP(mmHg) & $82.39 \pm 13.95$ & $82.25 \pm 15.27$ & 0.933 \\
\hline \multicolumn{4}{|l|}{ Blood data } \\
\hline Hemoglobin(g/L) & $99.92 \pm 19.80$ & $95.21 \pm 20.07$ & $0.031 *$ \\
\hline Albumin(g/L) & $36.80 \pm 6.39$ & $34.98 \pm 5.74$ & $0.006^{* *}$ \\
\hline Uric acid(mmol/L) & $379.78 \pm 134.65$ & $377.50 \pm 116.68$ & 0.868 \\
\hline Triglycerides(mmol/L) & $1.75 \pm 1.39$ & $1.88 \pm 1.35$ & 0.412 \\
\hline Total cholesterol(mmol/L) & $4.19 \pm 1.11$ & $4.08 \pm 1.13$ & 0.346 \\
\hline Dicarbonate(mmol/L) & $23.06 \pm 3.74$ & $22.24 \pm 3.74$ & $0.044^{*}$ \\
\hline Calcium(mmol/L) & $2.27 \pm 0.24$ & $2.26 \pm 0.24$ & 0.639 \\
\hline Phosphate(mmol/L) & $1.73 \pm 0.56$ & $1.75 \pm 0.61$ & 0.744 \\
\hline Parathormon(pg/ml) & $369.08 \pm 452.80$ & $379.08 \pm 383.00$ & 0.826 \\
\hline \multicolumn{4}{|l|}{$C T$} \\
\hline L1 attenuation (HU) & $168.90(137.75,197.00)$ & $159.10(118.15,212.00)$ & 0.363 \\
\hline \multicolumn{4}{|l|}{ Comorbidity } \\
\hline Diabetes(\%) & $60(35.29 \%)$ & $50(29.59 \%)$ & 0.262 \\
\hline Hypertension(\%) & $155(91.18 \%)$ & $141(83.43 \%)$ & $0.032^{*}$ \\
\hline CVD(\%) & $43(25.29 \%)$ & $34(20.12 \%)$ & 0.255 \\
\hline \multicolumn{4}{|l|}{ Medicine usage } \\
\hline Vitamin D(\%) & $76(44.71 \%)$ & $75(44.38 \%)$ & 0.952 \\
\hline Calciu supplements(\%) & $41(24.12 \%)$ & $45(26.63 \%)$ & 0.595 \\
\hline Cinacalcet(\%) & $31(18.24 \%)$ & $21(12.43 \%)$ & 0.138 \\
\hline ACEI/ARB(\%) & $52(30.59 \%)$ & $42(24.85 \%)$ & 0.238 \\
\hline \multicolumn{4}{|l|}{$F R A X(306)^{a}$} \\
\hline Major Osteoporosis & $3.78 \pm 2.56$ & $3.64 \pm 2.70$ & 0.637 \\
\hline Hip fracture & $1.61 \pm 1.85$ & $1.57 \pm 2.04$ & 0.881 \\
\hline
\end{tabular}

The values are shown as the mean $\pm S D$, median (interquartile range) or numbers $(\%),{ }^{*} P<0.05,{ }^{*} P<0.01$.

${ }^{a} 306$ of 339 patients agreed to complete the FRAX questionnaire.

$H D$ haemodialysis; BP blood pressure; FGF21 fibroblast growth factor 21; HU hounsfield unit; CVD cardiocerebrovascular disease; $A C E I$ angiotensin-converting enzyme; $A R B$ angiotensin receptor II antagonist; FRAX fracture risk assessment tool

subgroups based on 24-hour urine volume in HD patients, the area under the curve (AUC) of FGF21 in predicting osteoporosis were 0.657 (95\% $C I, 0.558$ to $0.755, P=0.001$ ) and 0.691 ( $95 \% C I, 0.606$ to $0.775, P=0.001$ ), respectively (Table 6). FGF21 has a good specificity ( $86.7 \%$ vs. $92.1 \%$ ) but low sensitivity $(44.2 \%$ vs. $41.8 \%)$ in two subgroups. In HD patients with 24-hour urine volume $>100 \mathrm{ml}$, the AUC of FGF21 combined with age in predicting osteoporosis was 0.837 (95\% CI, 0.778 to $0.896, P<0.001$ ) with better sensitivity (70.1\%) and specificity (81.4\%). In HD patients with 24-hour urine volume $\leq 100 \mathrm{ml}$, the AUC of FGF21 combined with age in predicting osteoporosis was 0.833 (95\% CI, 0.772 to $0.894, P<0.001$ ) with good sensitivity $(61.8 \%)$ and specificity $(90.5 \%)$. 

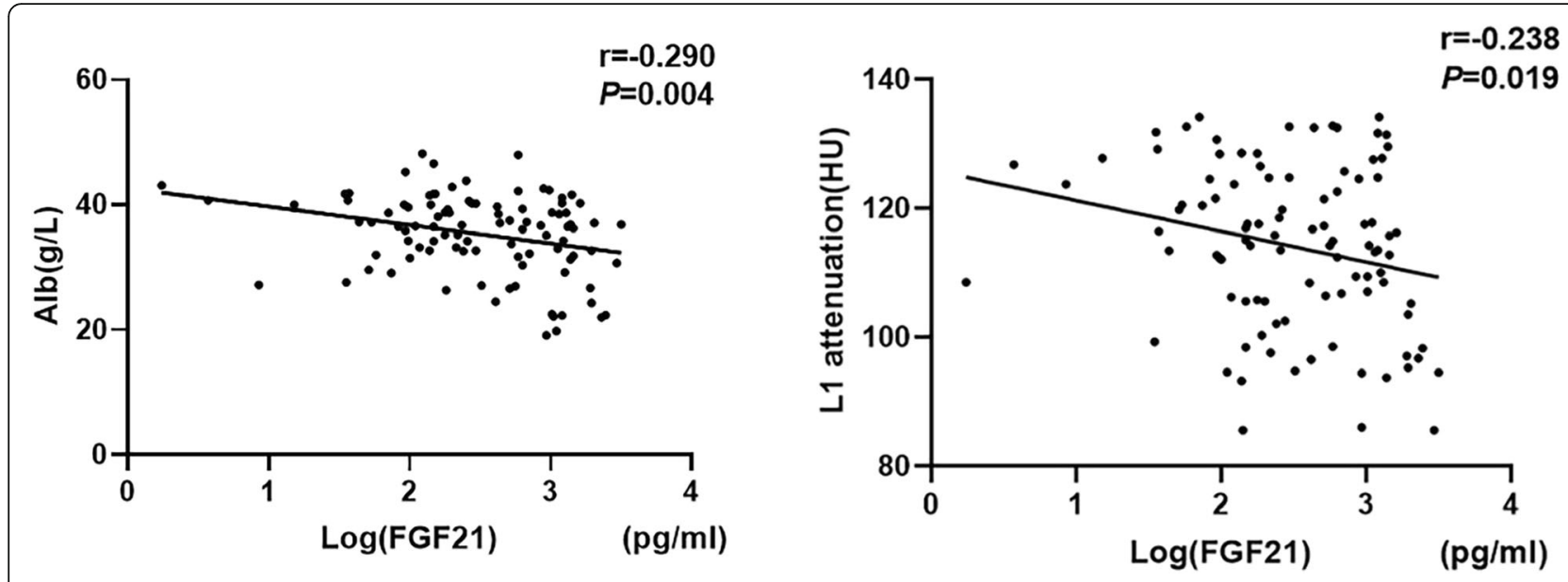

Fig. 3 Correlation of serum FGF21 and albumin and L1 attenuation in osteoporosis group of HD patients. Log (FGF21) was significantly correlated with (a) albumin $(r=-0.290, P<0.05)$; (b) L1 attenuation $(r=-0.238, P<0.05)$. FGF21, fibroblast growth factor 21; Alb, albumin

\section{Discussion}

In the present study, we showed that serum FGF21 levels were significantly higher in the osteoporosis group of patients on HD. FGF21 rather than FGF23 is independently and negatively associated with $\mathrm{CT}$ attenuation values in patients on HD. Furthermore, FGF21 combined with age showed good specificity (90.5\%) and sensitivity $(61.8 \%)$ for the prediction of osteoporosis in patients on HD with less residual renal function.

Many previous researches have showed the values of L1 trabecular attenuation at routine CT can identify the risk of osteoporosis in general population and the most optimized threshold was $135 \mathrm{HU}[22,23]$. In our study, we found that the mean age of the osteoporosis group was higher and that CT attenuation values declined with ageing in bivariate correlation analyses, which is in line with the characteristic of osteoporosis that the bone mass reaches its highest level in adolescence and then is subsequently lost with ageing [24]. In addition, we found that the percentage of vitamin D supplements was higher in the non-osteoporosis group, which may be due to the protective function of vitamin $\mathrm{D}$ on improving osteoporosis by affecting the number of osteoblasts, osteoclasts and osteocytes in bone [25].

FGF23 is a recently identified hormone that is produced in bone by osteocytes and osteoblasts [26]. In previous studies, FGF23 suppressed bone mineralization by inhibiting cell differentiation, number, activity and bone turnover [27-29]. In animal models, the role of FGF23 in regulating phosphate metabolism can be one causative factor of abnormal bone mineralization [30,31]. Our result that the FGF23 level was negatively associated with CT attenuation values was potent evidence for its role in bone loss as well. However, our results indicated that FGF23 was not an independent risk factor for osteoporosis (Table 3), and it had no value in predicting osteoporosis in this study (data not shown), even though Mirza $\mathrm{Ma}$ and Lane $\mathrm{Ne}$ et al. demonstrated that serum FGF23 levels were related independently to fracture risk in elderly men with decreased estimated glomerular filtration (eGFR) [32, 33]. These discrepancies may be due to the different methods used to measure bone mineral density, as dual-energy X-ray absorptiometry (DXA) was mostly used in previous studies.

FGF21 is another member of the FGF19 subfamily that is primarily secreted from the liver under physiological conditions and other sites, including adipose tissue, skeletal muscle, heart and kidney [34]. Multiple studies have shown that high-levels of serum FGF21 have association with the loss of bone mineral density in adults and postmenopausal women with normal renal function $[35,36]$. Moreover, its level increased progressively with a decline in renal function, as renal clearance is considered to be

Table 3 Bivariate correlation analyses for the correlations of L1 CT attenuation with serum FGF21 levels and other variables in patients on HD

\begin{tabular}{|c|c|c|c|c|c|c|c|c|c|c|c|c|c|c|}
\hline \multicolumn{15}{|c|}{ Variables } \\
\hline & Age & Dialysis & SBP & DBP & $\mathrm{Hb}$ & Alb & TG & $\mathrm{Ca}$ & $\mathrm{Pi}$ & iPTH & FGF21 & FGF23 & $\mathrm{MO}$ & HF \\
\hline$r$ & -0.440 & -0.120 & 0.030 & 0.274 & -0.019 & -0.027 & 0.017 & -0.022 & 0.089 & 0.105 & -0.136 & -0.151 & -0.383 & -0.411 \\
\hline$P$ value & $<0.001^{* *}$ & $0.028^{*}$ & 0.580 & $<0.001^{* *}$ & 0.721 & 0.623 & 0.761 & 0.692 & 0.104 & 0.053 & $0.012^{*}$ & $0.005^{* *}$ & $<0.001^{* *}$ & $<0.001^{* *}$ \\
\hline
\end{tabular}


Table 4 Multivariate linear regression analyses for the establishment of factors independently associated with CT attenuation

\begin{tabular}{|c|c|c|}
\hline Variables & $\beta(95 \% \mathrm{Cl})$ & $P$ value \\
\hline Age & $-1.021(-2.212,-0.512)$ & $<0.001^{* *}$ \\
\hline Dialysis duration & -0.040 & 0.467 \\
\hline BMl & -0.064 & 0.192 \\
\hline SBP & -0.042 & 0.547 \\
\hline DBP & $0.692(0.256,1.127)$ & $0.002^{* *}$ \\
\hline $\mathrm{TG}$ & -0.098 & 0.079 \\
\hline $\mathrm{TC}$ & -0.093 & 0.094 \\
\hline $\mathrm{Ca}$ & 0.005 & 0.923 \\
\hline $\mathrm{Pi}$ & -0.085 & 0.148 \\
\hline iPTH & 0.044 & 0.429 \\
\hline FGF21 & $-0.067(-0.104,-0.030)$ & $0.019^{*}$ \\
\hline FGF23 & -0.012 & 0.832 \\
\hline CVD & -0.084 & 0.147 \\
\hline DM & $-18.029(-31.217,-4.841)$ & $0.008^{*}$ \\
\hline Ca usage & -0.041 & 0.480 \\
\hline Vitamin D usage 0.044 & & 0.451 \\
\hline
\end{tabular}

Table 5 Multivariate linear regression analyses for the establishment of factors independently associated with FGF21

\begin{tabular}{lll}
\hline Variables & $\boldsymbol{\beta}(\mathbf{9 5} \% \mathbf{C l})$ & $\boldsymbol{P}$ value \\
\hline Age & 0.092 & 0.089 \\
Dialysis duration & 0.065 & 0.240 \\
BMI & 0.013 & 0.799 \\
SBP & 0.077 & 0.138 \\
DBP & 0.093 & 0.082 \\
TG & -0.053 & 0.309 \\
TC & 0.055 & 0.296 \\
Ca & $0.796(0.111,1.482)$ & $\mathbf{0 . 0 2 3}$ \\
Pi & 0.005 & 0.924 \\
iPTH & 0.000 & 0.994 \\
Alb & $-0.062(-0.088,-0.035)$ & $<0.001^{* *}$ \\
Dicarbonate & $-0.079(-0.121,-0.038)$ & $<\mathbf{0 . 0 0 1 * *}$ \\
CVD & -0.048 & 0.362 \\
DM & -0.019 & 0.726 \\
HBP & $-0.575(-1.020,-0.130)$ & $\mathbf{0 . 0 1 1 ^ { * }}$ \\
Ca usage & 0.039 & 0.460 \\
Vitamin D usage -0.005 & & 0.922 \\
\hline P & &
\end{tabular}

${ }^{*} P<0.05,{ }^{*} P<0.01$

FGF21 fibroblast growth factor 21; BMI body mass index; TC total cholesterol;

TG triglyceride; Ca calcium; Pi phosphate; $i P T H$ intact parathyroid hormone;

Alb albumin; CVD cardiocerebrovascular disease; DM diabetes mellitus;

$H B P$ high blood pressure the main route of FGF21 excretion [20]. Interestingly, we found that serum FGF21 levels were higher in our osteoporosis group than in the non-osteoporosis group in patients on HD (Table 1). Of note, our results also indicated that FGF21 was an independent risk factor for osteoporosis in multivariate linear regression analyses. Consistent with our results, a recent study conducted in patients undergoing haemodialysis also showed that serum FGF21 level was significantly negatively associated with BMD despite evaluated by DXA [37]. In addition to HD cohort, the relationship between FGF21 and bone mineral density was observed in normal kidney function as well [38]. The relevant mechanism could be explained by the following facts: (1) physiological or pharmacological elevation of FGF21 induced IGFBP1 expression, which could be secreted into circulation and stimulate osteoclast differentiation, bone resorption and reduce bone mass [18]; (2) a previous study showed that IGFBP1 was significantly increased in patients on HD compared to healthy controls [35], which is consistent with our result that IGFBP1 levels are nearly eight times higher in the osteoporosis group than in the nonosteoporosis group (data not shown); and (3) FGF21 functions to trigger intracellular calcium release [39] and increase phosphate intake [40], which is in line with our result that FGF21 had a positive relationship with serum calcium levels in this study (Table 5). Different from the role of FGF23 in regulating calcium and phosphorus levels, FGF21 is mainly involved in bone metabolism by influencing bone cells formation. Of course, the causative effect of FGF21 on osteoporosis in patients on HD and the exact mechanism of the involvement of FGF21 in the regulation of osteoporosis need to be further confirmed by large-sample RCT studies and related animal and cell experiments.

In this study, our results showed an approximately independent positive correlation between FGF21 and age $(P=0.089)$, although this relationship had insufficient statistical significance which may due to the relatively small sample size. Previous study has indicated that serum FGF21 level was increased in population with obesity or diabetes [41]. However, FGF21 levels has no difference between HD patients with or without comorbidity of diabetes in our study. The discordance may be attributed to following factors: (1) Eun SH et al. found that serum FGF21 level was only increased to 1.5 times in patients with type 2 diabetes compared with that in healthy individuals [42]. While in our study, serum FGF21 level of HD patients was 3-5 times higher than that in control group and this huge increase may mask the impact of diabetes on FGF21; (2) the independent correlation between diabetes and FGF21 can also be diminished by the high incidence of secondary glucose and lipid metabolic disorders in HD patients. 
Table 6 The area under the curve (AUC) of separated and grouped independently associated factors of L1 CT attenuation in ROC curve analyses in HD patients

\begin{tabular}{|c|c|c|c|c|c|c|}
\hline \multirow[t]{2}{*}{ Variables } & \multicolumn{2}{|l|}{ All HD patients } & \multicolumn{2}{|c|}{ HD patients with anuria } & \multicolumn{2}{|c|}{ HD patients without anuria } \\
\hline & $\mathrm{AUC}(95 \% \mathrm{Cl})$ & Pvalue & $\operatorname{AUC}(95 \% C l)$ & Pvalue & $\mathrm{AUC}(95 \% \mathrm{Cl})$ & Pvalue \\
\hline$\overline{\text { Age }}$ & $0.712(0.644,0.779)$ & $<0.001^{* *}$ & $0.756(0.681,0.832)$ & $<0.001 * *$ & $0.754(0.685,0.822)$ & $<0.001^{* *}$ \\
\hline FGF21 & $0.710(0.638,0.781)$ & $<0.001^{* *}$ & $0.657(0.558,0.755)$ & $0.001^{* *}$ & $0.691(0.606,0.775)$ & $<0.001^{* *}$ \\
\hline Age + FGF21 & $0.829(0.776,0.882)$ & $<0.001^{* *}$ & $0.837(0.778,0.896)$ & $<0.001^{* *}$ & $0.833(0.772,0.894)$ & $<0.001^{* *}$ \\
\hline
\end{tabular}

${ }^{*} P<0.05,{ }^{* *} P<0.01$

FGF21 fibroblast growth factor $21 ; H D$ haemodialysis

Currently, DXA and CT are the main techniques to assess bone loss and diagnose osteoporosis in patients on HD in clinical practice, and they still have some disadvantages, such as exposure to radiation and high cost. Besides, the 2009 KDIGO Guideline recommended that BMD testing not be performed routinely in patients with CKD G3a to G5D [1]. In our study, we found that FGF21 had a great value in predicting osteoporosis with a relatively high sensitivity (80.2\%). Moreover, the sensitivity of predicting osteoporosis could rise to $91.4 \%$ when FGF21 was combined with age. However, both of their specificities were below $50 \%$, which could be ascribed to the different residual renal function (RRF) in this research and complicated bone metabolism in CKD. Since serum FGF21 level is strongly dependent on RRF [20] that generally estimated by the 24-hour urine volume [43], we divided our osteoporosis HD patients into two subgroups based on the volume of 24-hour urine (24-hour urine volume $\leq 100 \mathrm{~mL}$ defined as no significant RRF [42]) and performed ROC analysis of FGF21 respectively to avoid relevant bias. As expected, the outstanding specificity (92.1\%) of FGF21 in HD patients with anuria proved our hypothesis. In contrast to FGF21, we observed that FGF23 had no value in predicting osteoporosis, although FGF23 had been proven to play a significant role in bone metabolism. The downside is that there was no difference in CT attenuation between the low and high level FGF21 subgroups in this study, this may due to the skewed distribution of FGF21 and it is difficult to find a suitable cut off value for the diagnosis of osteoporosis as a result. In general, either FGF21 alone or combined with age was an effective predictor of osteoporosis in patients on HD, especially those with less RRF. Our results can provide an easier way to identify patients with CKD with a high risk of osteoporosis and avoid extra radiation and cost. It may also provide a new therapeutic target for treating osteoporosis in patients on HD.

It must be admitted that our study also has some limitations: (1) the sample size in our study is relatively small, and more patients need to be enrolled to confirm the results; (2) other factors, such as 1,25-dihydroxyvitamin D and glucose, were not available in this study; (3) the association of FGF21 levels and DXA-based BMD levels were not explored; and (4) our results do not extend to other regions and ethnicities.

In conclusion, elevated FGF21 levels have a positive relationship with the incidence of osteoporosis in patients on HD. In addition, FGF21 alone or combined with age can be a predictive biomarker for osteoporosis in patients on HD, especially those with less RRF.

\section{Supplementary Information}

The online version contains supplementary material available at https://doi. org/10.1186/s12882-021-02393-z.

\section{Additional file 1.}

Acknowledgements

Not applicable.

\section{Authors' contributions}

Lili Zhu, Bi-Cheng Liu and Bin Wang contributed to the research idea and study design; Lili Zhu, Min Li, Qianqian Zha, Min Yang, Liqiong Jiang, Mingming Pan, QinYin and Meixia Xia contributed to data acquisition; Lili Zhu, Jirong Yu, Liqiong Jiang and Bin Wang contributed to data analysis/interpretation; Lili Zhu and Liqiong Jiang performed statistical analysis; Bi-Cheng Liu and Bin Wang provided supervision and mentorship. Each author contributed important intellectual content during manuscript drafting or revision and accepted accountability for the overall work by ensuring that questions pertaining to the accuracy or integrity of any portion of the work were appropriately investigated and resolved. The author(s) read and approved the final manuscript.

\section{Funding}

This work was supported by grants from the National Natural Science Foundation of China (No. 81700618), the Natural Science Foundation of Jiangsu Province (BK20181487), the China Young Nephrologist Research Project, and the Southeast University High Level Thesis Project to Bin Wang; the Medical research project of Jiangsu Commission of Health (H2019061) to Mingming Pan; the Health and Family Planning Commission of Jiangsu Province (KY2018105) to Min Yang, the National Natural Science Foundation of China (No. 81470922, 31671194, 81720108007, and 81670696), the National Key Research Program (2018YFC1314000) and the Clinic Research Center of Jiangsu Province (BL2014080) to Bi-Cheng Liu.

Availability of data and materials

The datasets analysed during the current study are available from the corresponding author on reasonable request.

\section{Declarations}

\section{Ethics approval and consent to participate}

The study protocol was approved by the Ethics Committee of Zhongda Hospital affiliated with Southeast University. The details of the study were explained to every patient; a signed informed consent was obtained from all subjects. All methods were confirmed to be carried out in accordance with relevant guidelines and regulations. 


\section{Consent for publication}

Not applicable.

\section{Competing interests}

The authors declare that they have no competing interests.

\section{Author details}

'Institute of Nephrology, Zhong Da Hospital, Southeast University School of Medicine, Nanjing, Jiangsu, China. ${ }^{2}$ Institute of Nephrology, the Third Affiliated Hospital of Soochow University, Changzhou, China.

Received: 17 November 2020 Accepted: 26 April 2021

Published online: 19 May 2021

\section{References}

1. Ketteler M, Block GA, Evenepoel P, Fukagawa M, Herzog CA, McCann L, Moe SM, Shroff R, Tonelli MA, Toussaint ND: Executive summary of the 2017 KDIGO Chronic Kidney Disease-Mineral and Bone Disorder (CKD-MBD) Guideline Update: what's changed and why it matters. Kidney international, 92(1):26-36.

2. Rivara MB, Ravel V, Kalantar-Zadeh K, Streja E, Lau WL, Nissenson AR, Kestenbaum B, de Boer IH, Himmelfarb J, Mehrotra R. Uncorrected and Albumin-Corrected Calcium, Phosphorus, and Mortality in Patients Undergoing Maintenance Dialysis. J Am Soc Nephrol. 2015;26(7):1671-81.

3. Graciolli FG, Neves KR, Barreto F, Barreto DV, Dos Reis LM, Canziani ME, Sabbagh Y, Carvalho AB, Jorgetti V, Elias RM et al: The complexity of chronic kidney disease-mineral and bone disorder across stages of chronic kidney disease. Kidney international 2017, $91(6): 1436-1446$.

4. Torres PAU, Cohen-Solal M: Evaluation of fracture risk in chronic kidney disease. J Nephrol 2017, 30(5):653-661.

5. Maravic M, Ostertag A, Torres PU, Cohen-Solal M. Incidence and risk factors for hip fractures in dialysis patients. Osteoporosis Int. 2014;25(1):159-65.

6. Rix M, Andreassen H, Eskildsen P, Langdahl B, Olgaard K: Bone mineral density and biochemical markers of bone turnover in patients with predialysis chronic renal failure. Kidney international 1999, 56(3):1084-1093.

7. Cunningham J, Sprague SM, Cannata-Andia J, Coco M, Cohen-Solal M, Fitzpatrick L, Goltzmann D, Lafage-Proust MH, Leonard M, Ott S, et al. Osteoporosis in chronic kidney disease. Am J Kidney Dis. 2004;43(3):566-71.

8. Fuggle NR, Curtis EM, Ward KA, Harvey NC, Dennison EM, Cooper C: Fracture prediction, imaging and screening in osteoporosis. Nature reviews Endocrinology 2019, 15(9):535-547.

9. Jamal SA, West SL, Miller PD: Fracture risk assessment in patients with chronic kidney disease. 23(4):1191-1198.

10. De Vriese AS. Should Statins Be Banned from Dialysis? J Am Soc Nephrol. 2017;28(6):1675-6.

11. Xiao DM, Wu Q, Fan WF, Ye XW, Niu JY, Gu Y: Effect of serum FGF-23, MGP and fetuin-A on calcium-phosphate metabolism in maintenance hemodialysis patients. Hemodialysis Int Symposium Home Hemodialysis 2013, 17(4):483-492.

12. Guo YC, Yuan Q. Fibroblast growth factor 23 and bone mineralisation. Int J Oral Sci. 2015;7(1):8-13.

13. Vogt I, Haffner D, Leifheit-Nestler M: FGF23 and Phosphate-Cardiovascular Toxins in CKD. Toxins 2019, 11(11).

14. Bouksila M, Mrad M, Kaabachi W, Kalai E, Smaoui W, Rekik S, Krir A, Issaoui N, Hamzaoui K, Sahli H et al: Correlation of Fgf23 and Balp with Bone Mineral Density in Hemodialysis Patients. Journal of medical biochemistry 2019, 38(4):418-426.

15. Yang WP, Chang HH, Li HY, Lai YC, Huang TY, Tsai KS, Lin KH, Lin DT, Jou ST, Lu MY et al: Iron Overload Associated Endocrine Dysfunction Leading to Lower Bone Mineral Density in Thalassemia Major. The Journal of clinical endocrinology and metabolism 2020.

16. Wohlfahrt P, Melenovsky V, Kotrc M, Benes J, Jabor A, Franekova J, Lemaire S, Kautzner J, Jarolim P: Association of Fibroblast Growth Factor-23 Levels and Angiotensin-Converting Enzyme Inhibition in Chronic Systolic Heart Failure. JACC Heart failure 2015, 3(10):829-839.

17. Isakova T, Cai X, Lee J, Katz R, Cauley JA, Fried LF, Hoofnagle AN, Satterfield S, Harris TB, Shlipak MG, et al. Associations of FGF23 With Change in Bone Mineral Density and Fracture Risk in Older Individuals. J Bone Mineral Res. 2016:31(4):742-8.
18. Wang X, Wei W, Krzeszinski JY, Wang Y, Wan Y: A Liver-Bone Endocrine Relay by IGFBP1 Promotes Osteoclastogenesis and Mediates FGF21-Induced Bone Resorption. Cell metabolism 2015, 22(5):811-824.

19. Kharitonenkov A, Shiyanova TL, Koester A, Ford AM, Micanovic R, Galbreath EJ, Sandusky GE, Hammond LJ, Moyers JS, Owens RA et al: FGF-21 as a novel metabolic regulator. The Journal of clinical investigation 2005, 115(6): 1627-1635.

20. Anuwatmatee S, Tang S, Wu BJ, Rye KA, Ong KL: Fibroblast growth factor 21 in chronic kidney disease. Clinica chimica acta; international journal of clinical chemistry 2019, 489:196-202.

21. Wei W, Dutchak PA, Wang X, Ding X, Wang X, Bookout AL, Goetz R, Mohammadi M, Gerard RD, Dechow PC et al: Fibroblast growth factor 21 promotes bone loss by potentiating the effects of peroxisome proliferatoractivated receptor gamma. Proceedings of the National Academy of Sciences of the United States of America 2012, 109(8):3143-3148.

22. Pickhardt PJ, Pooler BD, Lauder T, del Rio AM, Bruce RJ, Binkley N. Opportunistic screening for osteoporosis using abdominal computed tomography scans obtained for other indications. Ann Internal Med. 2013; 158(8):588-95.

23. Jang S, Graffy PM, Ziemlewicz TJ, Lee SJ, Summers RM, Pickhardt PJ: Opportunistic Osteoporosis Screening at Routine Abdominal and Thoracic CT: Normative L1 Trabecular Attenuation Values in More than 20000 Adults. Radiology 2019, 291 (2):360-367.

24. Jilka RL. The relevance of mouse models for investigating age-related bone loss in humans. J Gerontology Series A, Biological Sci Med Sci. 2013;68(10): 1209-17.

25. Hou YC, Wu CC, Liao MT, Shyu JF, Hung CF, Yen TH, Lu CL, Lu KC: Role of nutritional vitamin D in osteoporosis treatment. Clinica chimica acta; international journal of clinical chemistry 2018, 484:179-191.

26. Liu S, Guo R, Simpson LG, Xiao Z-S, Burnham CE, Quarles LD: Regulation of Fibroblastic Growth Factor 23 Expression but Not Degradation by PHEX. Journal of Biological Chemistry, 278(39):37419-37426.

27. Wang H, Yoshiko Y, Yamamoto R, Minamizaki T, Kozai K, Tanne K, Aubin JE, Maeda N: Overexpression of fibroblast growth factor 23 suppresses osteoblast differentiation and matrix mineralization in vitro. Journal of bone and mineral research: the official journal of the American Society for Bone and Mineral Research 2008, 23(6):939-948.

28. Shalhoub V, Ward SC, Sun B, Stevens J, Renshaw L, Hawkins N, Richards WG: Fibroblast growth factor 23 (FGF23) and alpha-klotho stimulate osteoblastic MC3T3.E1 cell proliferation and inhibit mineralization. Calcified tissue international 2011, 89(2):140-150.

29. Allard L, Demoncheaux N, Machuca-Gayet I, Georgess D, Coury-Lucas F, Jurdic P, Bacchetta J: Biphasic Effects of Vitamin D and FGF23 on Human Osteoclast Biology. Calcified tissue international 2015, 97(1):69-79.

30. Liu S, Tang W, Zhou J, Vierthaler L, Quarles LD. Distinct roles for intrinsic osteocyte abnormalities and systemic factors in regulation of FGF23 and bone mineralization in Hyp mice. Am J Phys Endocrinology Metab. 2007; 293(6):E1636-1644

31. Aono Y, Yamazaki Y, Yasutake J, Kawata T, Hasegawa H, Urakawa I, Fujita T, Wada M, Yamashita T, Fukumoto S, et al. Therapeutic effects of anti-FGF23 antibodies in hypophosphatemic rickets/osteomalacia. J Bone Mineral Res. 2009;24(11):1879-88.

32. Mirza MA, Karlsson MK, Dan M, Orwoll E, Ohlsson C, Ljunggren Ö, Larsson TE: Serum fibroblast growth factor-23 (FGF-23) and fracture risk in elderly men. Journal of Bone \& Mineral Research 2011, 26.

33. Lane NE, Parimi N, Corr M, Yao W, Cauley JA, Nielson CM, Ix JH, Kado D, Orwoll E. Osteoporotic Fractures in Men Study G: Association of serum fibroblast growth factor 23 (FGF23) and incident fractures in older men: the Osteoporotic Fractures in Men (MrOS) study. J Bone Mineral Res. 2013;28(11):2325-32.

34. Staiger H, Keuper M, Berti L, Hrabě de Angelis M, Hring H-U: Fibroblast Growth Factor 21 - Metabolic Role in Mice and Men. Endocrine reviews.

35. Hao RH, Gao JL, Li M, Huang W, Zhu DL, Thynn HN, Dong SS, Guo Y: Association between Fibroblast Growth Factor 21 and Bone Mineral Density in Adults. Endocrine 2018, 59(2):296-303.

36. Hoon SC, Hyang AL, Sang WK, Eun HC: Association between Serum Fibroblast Growth Factor 21 Levels and Bone Mineral Density in Postmenopausal Women. Endocrine 2018, 33(2):273-277.

37. Wu YT, Hsu BG, Wang CH, Lin YL, Lai YH, Kuo CH: Lower Serum Fibroblast Growth Factor 21 Levels are Associated with Normal Lumbar Spine Bone Mineral Density in Hemodialysis Patients. International journal of environmental research and public health 2020, 17(6). 
38. Iglesias P, Diez JJ, Fernandez-Reyes MJ, Mendez J, Bajo MA, Aguilera A, Selgas R: Growth hormone, IGF-I and its binding proteins (IGFBP-1 and - 3) in adult uraemic patients undergoing peritoneal dialysis and haemodialysis. Clinical endocrinology 2004, 60(6):741-749.

39. Coate KC, Hernandez G, Thorne CA, Sun S, Le TDV, Vale K, Kliewer SA, Mangelsdorf DJ: FGF21 Is an Exocrine Pancreas Secretagogue. Cell metabolism 2017, 25(2):472-480.

40. Pineda C, Rios R, Raya Al, Rodriguez M, Aguilera-Tejero E, Lopez I: Hypocaloric Diet Prevents the Decrease in FGF21 Elicited by High Phosphorus Intake. Nutrients 2018, 10(10).

41. Woo YC, Xu A, Wang Y, Lam KS: Fibroblast growth factor 21 as an emerging metabolic regulator: clinical perspectives. Clinical endocrinology 2013, 78(4): 489-496.

42. Hong ES, Lim C, Choi HY, Lee YK, Ku EJ, Moon JH, Park KS, Jang HC, Choi SH. Plasma fibroblast growth factor 21 levels increase with ectopic fat accumulation and its receptor levels are decreased in the visceral fat of patients with type 2 diabetes. BMJ Open Diab Res Care. 2019;7(1):e000776.

43. Andrew IC, Vishwa S, Jeehyoung K, Heejung B: Estimating residual native kidney urea clearance in hemodialysis patients with and without 24-hour urine volume. Kidney Med 2019, 1(6): 376-382.

\section{Publisher's Note}

Springer Nature remains neutral with regard to jurisdictional claims in published maps and institutional affiliations.

Ready to submit your research? Choose BMC and benefit from:

- fast, convenient online submission

- thorough peer review by experienced researchers in your field

- rapid publication on acceptance

- support for research data, including large and complex data types

- gold Open Access which fosters wider collaboration and increased citations

- maximum visibility for your research: over $100 \mathrm{M}$ website views per year

At $\mathrm{BMC}$, research is always in progress.

Learn more biomedcentral.com/submissions 